\title{
Wiener Verbindungen der Prager Presse im ersten Jahr ihres Bestehens (1921). Prolegomena zu weiteren möglichen Forschungen
}

Michael Topor, Le journal Prager Presse et ses relations viennoises dans la première année de son existence (1921). Prolégomènes à des recherches futures Michael Topor, Vienna connections of Prager Presse in his first year (1921). Prolegomena on further possible research

\section{Michal Topor}

Traducteur : Ilka Giertz

\section{(2) OpenEdition}

\section{Journals}

Édition électronique

URL : https://journals.openedition.org/austriaca/785

DOI : 10.4000/austriaca.785

ISSN : 2729-0603

\section{Éditeur}

Presses universitaires de Rouen et du Havre

\section{Édition imprimée}

Date de publication : 1 décembre 2019

Pagination : 117-148

ISBN : 979-10-240-1454-8

ISSN : 0396-4590

Référence électronique

Michal Topor, „Wiener Verbindungen der Prager Presse im ersten Jahr ihres Bestehens (1921).

Prolegomena zu weiteren möglichen Forschungen“, Austriaca [Online], 88-89 | 2019, Online erschienen am: 31 Dezember 2020, abgerufen am 24 Oktober 2022. URL: http://journals.openedition.org/ austriaca/785 ; DOI: https://doi.org/10.4000/austriaca.785 
Michal Topor

Institut pro studium literatury,

o. p. s. Institut für Literaturforschung, Prag

\section{Wiener Verbindungen der Prager Presse im ersten Jahr ihres Bestehens (1921) Prolegomena zu weiteren möglichen Forschungen}

1.

Die folgende Studie soll die Verbindungen des Prager Periodikums zu Wien als dem einstigen Zentrum der untergegangenen Monarchie wie auch als Hauptstadt des neuen Nachbarlandes beleuchten. Gleichzeitig kann sie jedoch (dem Anspruch bibliografischer Gründlichkeit folgend) synekdochisch die Grenzen der bisherigen Erforschung und damit auch Erkenntnis - von etwas aufzeigen, das vielleicht als Migration von Texten und Personen innerhalb eines europäischen oder zumindest mitteleuropäischen Netzes von Kontakten und Publikationsplattformen bezeichnet werden könnte. Solange kein gemeinsames, kommunizierbares (d. h. übernational und überstaatlich angelegtes) Instrument existiert ${ }^{1}$, das eine bio- und bibliografisch genaue Vorstellung vom Anteil einzelner Autoren und Autorinnen an den jeweiligen europäischen Periodika ermöglicht (von der redaktionellen Mitarbeit bis hin zum sporadischen Verfassen von Beiträgen), werden die Forscher (vornehmlich unbewusst) auch weiter auf lückenhaften Pfaden wandeln, betört hier und da von glücklichen, doch gleichfalls

1. Vgl. Hans-Gert Roloff, „Das Problem der 'Datenmengen' in der Literaturwissenschaft“, in Donald G. Daviau, Herbert Arlt (Hg.), Geschichte der österreichischen Literatur. Teil 2, St. Ingebert (= Österreichische und internationale Literaturprozesse, Bd. 3, Teil 2), Röhrig Universitätsverlag, 1996, S. 685-706; Günther Mühlberger, „Bibliographische Probleme und Chancen im Zeichen globaler Vernetzung“, ebd., S. 697-706; Jutta Weber, „Die Zentralkartei der Autographen - heutige Datenbanken - Literaturgeschichtsschreibung", ebd., S. 707-716. 
lückenhaften Funden. Es werden weiterhin Monografien, Anthologien und Sammelbände entstehen, die das Ganze eines publizierten Werks nur hypothetisch berücksichtigen.

Gleiches gilt auch für meine Studie. So lässt sich z. B. die Bedeutung der Prager Presse (als Ort des Schreibens über Wien wie auch als Absatzmarkt für Texte von Autoren, die auf verschiedene Weise mit dem Wiener Milieu verbunden waren) kaum verlässlich beurteilen, wenn wir nicht wissen, inwieweit diese Autoren ihre (anderen) Texte parallel dazu auch den Redaktionen weiterer (auch nicht-deutschsprachiger) Prager und tschechischer bzw. europäischer Blätter anboten, kurz: wenn wir die individuellen Publikationsspektren nicht kennen, die ggf. einen breiten und unerwarteten Umfang hatten. Dabei geht es was die klägliche Fragmentarität jeglicher „interkultureller Analysen“2 anbelangt - nicht nur um die erfassbare Oberfläche, sondern auch um die schwerer zu fassenden Komplexe einzelner Diskurse, Begriffe, Themen- und Rezeptionslinien, vereinfacht gesagt: um Worte und Dinge, die kreuz und quer durch Europa zirkulierten.

Die Tageszeitung Prager Presse erschien ab dem 27. März 1921 im Verlag der Aktiengesellschaft Orbis und unterstand somit den Meinungen und Entscheidungen von deren Verwaltungsrat, insbesondere dem Wort Jan Hájeks, Leiter der Nachrichtenabteilung im Außenministerium Edvard Benešs (welches de facto in beträchtlichem Maß an der Finanzierung von Orbis beteiligt war ${ }^{3}$ ). Das Mitarbeiternetz der neuen Zeitung erstreckte sich bald auf ein breiteres (über die Tschechoslowakei hinausgehendes) deutschsprachiges Gebiet, so u. a. auch auf Wien. Etliche der „Wiener" Verbindungen hatten ihren Ausgangspunkt in persönlichen Kontakten der zwei wichtigsten Redakteure des Blattes - Otto Picks und des Chefredak-

2. Vgl. z. B. Jörg Krappmann, Allerhand Übergänge. Interkulturelle Analysen der regionalen Literatur in Böhmen und Mähren sowie der deutschen Literatur in Prag (1890-1918), Bielefeld, transcript Verlag, 2013.

3. Die Prager Presse ist, wenn auch bislang unvollständig (ihre Herausgabe endete am 31.12.1938), online unter www.digitalniknihovna.cz/mzk zugänglich. Als bislang unübertroffene Darstellung des Blattes siehe Barbara Köpplová, Prager Presse - založení listu a jeho kulturně politická úloha v letech 1921-1925 [Die Prager Presse - Gründung und kulturpolitische Rolle in den Jahren 1921-1925], Prag, 1986 (Dissertation). Zur Rolle der Prager Presse im damaligen Pressesystem und generell zur journalistischen Berichterstattung in der Zeit nach dem I. Weltkrieg (auch im Verhältnis zu Teilen des Staatsapparats) vgl. Karel Hoch, „Česká žurnalistika v době př́tomné“ [Tschechischer Journalismus der Gegenwart], in Československá vlastivěda. Teil VII. Písemnictví, Praha, Bohumil Janda - Sfinx, 1933, S. 496-514. 
teurs Arne Laurin - aus der Zeit vor und während des I. Weltkriegs: Beide hatten die letzten Monate der österreichisch-ungarischen Monarchie in dem legendären Kriegspressequartier verbracht, wo sie sich, ähnlich wie Franz Blei ${ }^{4}$, Paris Gütersloh oder Egon Erwin Kisch (mit dem Laurin bereits vor dem Krieg befreundet war), unter Leitung Robert Musils an der Redaktion einer viersprachig (deutsch [Heimat], ungarisch, tschechisch [Domov] und slowenisch) erscheinenden, loyal-proösterreichischen Propagandazeitschrift beteiligten ${ }^{5}$. Hier begegneten sie - nicht zuletzt in den Lieblingscafés ihrer Kollegen (vor allem im Café Central oder Herrenhof) - zahlreichen ihrer Freunde und Bekannten wie z. B. dem Kritiker, Essayisten und Prosaiker Robert Müller ${ }^{6}$ oder der Publizistin Ea von Allesch (Redakteurin der Monatsillustrierten Moderne Welt ${ }^{7}$ ). Zur Redaktion des oben genannten Propagandablattes gehörten auch der Journalist Josef Isidor Langstein ${ }^{8}$ und der in Wien geborene Wilhelm Neffzern. Ersterer trug Ende 1920/Anfang 1921 intensiv zum Aufbau des Mitarbeiternetzes der Prager Presse ${ }^{9}$ bei und fungierte später

4. Vgl.: „Wenn ich im Janner [sic] in Prag lesen kann, werd ich mich sehr freuen, schon deshalb, weil ich dich wiedersehe, mein lieber guter alter Laurin, Leidensgenosse aus alten Tagen“ (F. Blei an A. Laurin, München, 18.12.1921, Literární archiv Památníku národního písemnictví / Denkmal des nationalen Schrifttums, Literaturarchiv, Prag; weiter LA PNP/, Nachlass Arne Laurin /weiter AL/).

5. Siehe Robert Musil, Briefe nach Prag, Barbara Köpplová, Kurt Krolop (Hg.), Reinbek bei Hamburg, Rowohlt, 1971.

6. Im September 1920 schreibt Müller an Laurin, dass er kürzlich von ihm gehört habe: „Ich habe schon öfter an Sie gedacht und Sie sind mir durchaus nicht aus der Erinnerung entschwunden. Mit Robert Musil, dem dritten in unserem Gründerbunde, bin ich öfter zusammen“ (R. Müller an Arne Laurin, Wien, 21.9.1920, LA PNP, AL), vgl. Michal Topor, „Böhmische Peripherien in der Publizistik Robert Müllers“, in Germanoslavica 29, 2018, Nr. 1, im Druck.

7. Zu Ea von Allesch siehe Frauke Severit, „Ea von Allesch (1875-1953). Ein Spiegelbild der Welt kannst Du nicht sein!", in dies. (Hg.), Das alles war ich. Politikerinnen, Künstlerinnen, Exzentrikerinnen der Wiener Moderne, Wien, Böhlau, 1998, S. 249-285, dort S. 269-270.

8. Vgl. eine Erinnerung Jiří Červenýs, der Josef Langstein aus dem Wiener Parlament kannte. Langstein hatte ihn um einen „Beitrag für Domov, eine Zeitschrift für tschechischsprachige österreichische Soldaten, gebeten, deren Redakteur Arne Laurin war“ (Jiří Červený, Červená sedma [Die rote Sieben], Praha, Orbis, 1959, S. 137-138).

9. Josef Langstein ist als Kontaktperson auch in den Briefen erwähnt, die der Wiener Journalist, einstige Mitbegründer und spätere Redakteur der Wochenzeitung Die Zeit Heinrich Kanner im März desselben Jahres an die Organisatoren der Prager Presse adressierte, wobei er betonte, dass er zu beschäftigt sei und daher nicht als Mitarbeiter des geplanten Blattes angeführt werden könne und wolle (H. Kanner an [„Sehr geehrte Herren!"], Wien, 13. und 21.3.1921, LA PNP, AL). In der zweiten Septemberhälfte 
als deren Wiener Korrespondent, Letzterer wurde zum verantwortlichen Redakteur des Blattes ernannt und war bis 1926 als solcher tätig.

Als die Redaktion des obskuren Prager nationalistischantisemitischen Blattes Staroslovan Anfang Juni 1921 mit einer (bereits eröffneten) Serie von Invektiven gegen die Prager Presse und deren politischen Hintergrund fortfuhr, vergaß sie nicht, auch die Wiener Verbindungen der Zeitung zu karikieren: „Man schickte den jüdischen Oberredakteur Lustig (Laurin) mit einem hohen Taschengeld nach Wien, damit er sich im Caffé Graben, im Siller, im Graben-Keller und Rathauskeller präsentieren könne $[. . .]^{10 “}$. - Die solide finanzielle Basis der neuen Tageszeitung förderte zweifellos deren Anziehungskraft. Nicht zu unterschätzen ist jedoch - bei aller Vorsicht - die Macht der ideellen Argumentation, insbesondere des Verweises auf den hinter dem Blatt stehenden Willen Masaryks sowie auf die proklamierte Vision einer großen Verständigung. „[U]nser Blatt will und wird ein objektiv informierendes Blatt sein, ein europäisch arbeitendes Blatt, ein Blatt im europäischem [sic] Geiste und von europäischer Gesinnung, von europäischer Toleranz und ein Anwalt der Ideen rascher Herstellung des Friedenszustandes und der Zusammenarbeit der europäischen Nationen", stand im Leitartikel der ersten Ausgabe ${ }^{11}$.

Gleich auf Seite zwei zitierte die Redaktion jedoch in exponierter Weise die konstruktiv-entgegenkommenden Worte des österreichischen Bundespräsidenten Michael Hainisch, und zwei Seiten weiter findet sich ein Text, der dem Blatt - als Essenz eines Vortrags vor der Wiener Soziologischen Gesellschaft - von Karl Renner angeboten wurde $^{12}$. Einige weitere Berichte aus Wien sind mit „ $\Delta$ “ unterzeichnet (häufig auch in den nachfolgenden Wochen, z. T. mit dem Zusatz „Priv.-

1921 schrieb Kanner an Laurin: „Es ist sehr liebenswürdig von Ihnen, mich durch Herrn Langstein immer wieder zur Mitarbeit auffordern zu lassen“ (Wien, 20.9.1921, LA PNP, AL). Bald darauf änderte er jedoch seine reservierte Haltung und wurde zu einem der wichtigsten Wiener Mitarbeiter des Blattes - siehe weiterer Text.

10. Orig.: „[...] poslán byl židovský oberredaktor Lustig (Laurin) do Vídně s velkou apanáží, aby se mohl reprezentovat v Caffé Graben, Siller, v Graben-Kelleru a Rathauskelleru [...]“, in: „Jak vznikla 'Prager Presse“ [„Die Gründung der 'Prager Presse'], in Staroslovan 3, 1921, Nr. 20, 5. 6., S. 3.

11. „Unser Programm“, in Prager Presse 1, 1921, Nr. 1, 27.3., S. 1. Die kursive Hervorhebung ist aus dem Text übernommen.

12. „Präsident Hainisch über die Beziehungen Österreichs zur Tschechoslowakei. , Masaryk - Lehrmeister praktischer Philosophie“", ebd., S. 2; Karl Renner, „Vereinigte Staaten von Mitteleuropa“, ebd., S. 4. 
Telegramm“ und auch aus Innsbruck, Linz oder Graz; hierbei handelte es sich wahrscheinlich um den bereits erwähnten J. I. Langstein ${ }^{13}$ ). Ein Wiener „Finanzbrief“ ist mit „N.“ signiert. Separater Bestandteil der ersten Ausgabe war zudem eine belletristische Osterbeilage. Die Texte für diese stammten u. a. von Hugo von Hofmannsthal, Stefan Zweig und Ea von Allesch ${ }^{14}$. Diese Anfangszusammensetzung umreißt bereits die grundlegenden, später weiterentwickelten Wiener Dimensionen des Blattes: eine, breitere, menschenbezogenere, nämlich biografische Dimension - diese beruhte auf der unterschiedlichen, zeitlich wandelbaren (de facto $\mathrm{z}$. T. eher in der Vergangenheit liegenden oder sehr sporadischen ${ }^{15}$ ) Wiener Verankerung bzw. Herkunft der Autoren,

13. Vgl.: „Wegen der Theater schreibe ich Ihnen das nächstemal, denn ich glaube, daß ich das hier durch die Korporation der Auslandskorrespondenten machen kann und muß. Ich werde anfang $[s i c]$ nächster Woche darüber mit Langstein sprechen und es womöglich ordnen, ohne Sie zu bemühen“; siehe auch: „Sehr geehrter Herr Langstein / Arne Laurin hat mir den Wunsch ausgesprochen, daß ich öfters als bisher vor der ausführlichen Kritik kurze Berichte über Theaterereignisse durch Ihre freundliche Vermittlung sofort telefonisch geben soll“ (R. Musil an A. Laurin, Wien, 9.3.1921; R. Musil an J. Langstein, 6.10.1921 - Robert Musil, Briefe 1901-1942, Adolf Frisé (Hg.), Reinbek bei Hamburg, Rowohlt Verlag, 1981, S. 218, 242).

14. Hugo von Hofmannsthal, „Der Ersatz für die Träume. Eine kleine Betrachtung“, ebd., Ostern. Beilage der Prager Presse, S. 17-18; Stefan Zweig, „Die Tragik der Vergesslichkeit“, ebd., S. 19-20.

15. So beziehe ich in meine Studie z. B. auch Beiträge von F. Blei und P. Gütersloh ein, die sich 1921 de facto eher nicht in Wien aufhielten. Gütersloh war 1919-1921 Chefregisseur am Münchener Schauspielhaus, und auch Blei hielt sich, als er für die Prager Presse zu schreiben begann, hauptsächlich in München auf („Lieber Herr Laurin, / gern schreib ich dir das für dein Blatt“, schrieb Blei bereits in der zweiten Januarhälfte 1921, und er bot an: „[I]ch schreibe dir einmal im Monat einen ,Münchner Brief“", 24.1.1921, LA PNP, AL). Er war allerdings oft in Wien zu Gast (Silvia Bonacchi - Emanuela Veronica Fanelli, „Ein nie gesättigtes Verlangen nach Geist...“. Zur Beziehung zwischen Franz Blei und Robert Musil, in: Dietrich Harth (Hg.), Franz Blei. Mittler der Literaturen, Hamburg, Europäische Verlagsanstalt, 1997, S. 108-138, dort S. 126, 121, vgl. auch Franz Blei, Briefe an Carl Schmitt 1917-1933, Angela Reinthal, Wilhelm Kühlmann (Hg.), Heidelberg, Manutius Verlag, 1995, S. 23-37). Nicht berücksichtigt habe ich hier hingegen Hans Natonek, der zwar ebenfalls (noch vor dem I. Weltkrieg) kurzzeitig in Wien weilte und auch später in einigen Wiener Zeitschriften publizierte (vgl. Steffi Böttger, Für immer Fremd. Das Leben des jüdischen Schriftstellers Hans Natonek, Leipzig, Lehmstedt, 2013, S. 27-31). Für Natoneks Zusammenarbeit mit der Prager Presse war jedoch ausschließlich sein Leipziger Kontext entscheidend. Bezeichnend ist, dass S. Böttger in ihren Sammelband Im Geräusch der Zeit. Gesammelte Publizistik 19141933 (Leipzig, Lehmstedt, 2006), der z. B. den Text Wiedersehen mit Wien vom Januar 1920 enthält, nicht einen einzigen der vielen in der Prager Presse gedruckten Texte aufgenommen hat - als wären ihr diese nicht bekannt. Ebenfalls nur kurz erwähnt habe ich die Mitarbeit Camill Hoffmanns, dessen Laufbahn in früheren Jahren (19021912) eng mit Wien verknüpft war (vgl. Pavel Polák, Camill Hoffmann. Eine Biographie, 
und eine zweite, sagen wir: topologische Dimension auf der Ebene von Berichterstattung (v. a. über aktuelle politische Ereignisse und volkswirtschaftliche Fragen) und Artikeln über das Geschehen in der Wiener österreichischen Kunstszene - ein imaginärer „Stadttext Wiens ${ }^{\text {"16 }}$.

2.

Wichtigster Agent der Prager Presse war zweifellos Robert Musil. „Ich mag nicht, dass alles durch Musil geht", beschwerte sich bei Laurin Anfang März 1921 Ea von Allesch im Zusammenhang mit verschiedenen Kommunikationsproblemen (einem fehlenden Brief, den E. E. Kisch an Laurin senden sollte, der Tatsache, dass Laurin während eines Wien-Aufenthalts Polgar nicht aufgesucht hatte). Ihre Haltung gegenüber Musils (Kaffeehaus-) Kreis stilisierte sie wiederholt als eine betont distanzierte. So schrieb sie zum Beispiel: „Ich verkehre nicht mehr mit ihnen und gehe nie mehr in irgend ein Cafe' ${ }^{117}$. Musil war Laurin beim Aufbau eines Mitarbeiterkreises behilflich. Anfang März schrieb er diesbezüglich an Alban Berg: „In Prag wird nächster Zeit eine große deutsche Zeitung zu erscheinen beginnen, die von einer Masaryk nahestehenden Seite herausgegeben wird. Ich bin gebeten worden, in Wien die kulturelle und künstlerische Vertretung zu übernehmen und außer mir arbeiten Robert Müller, Franz Werfel u. a. mit" (Berg nahm das Angebot letztlich nicht $a^{18}{ }^{18}$. Auf Wunsch Laurins

Praha, Filozofická fakulta Univerzity Karlovy, 2006 (Diplomarbeit), S. 17-26). Zu Erscheinungsbeginn der Prager Presse war er jedoch bereits in der tschechoslowakischen Botschaft in Berlin tätig.

16. Vgl. Stefan Simonek, „Urbane Lektüren in extremis: Der Stadttext Wiens um 1900 aus metasprachlicher, marginaler und karnevalisierter Perspektive", in Helga Mitterbauer, András F. Balogh (Hg.), Zentraleuropa. Ein hybrider Kommunikationsraum, Wien, Praesens Verlag, 2006, S. 143-155.

17. E. von Allesch an A. Laurin, Wien, 1.3.1921, LA PNP, AL. - Bereits im Februar zeigte sich E. von Allesch verwundert, warum man anstelle von Musil nicht Polgar als Wiener Theaterkorrespondenten engagiere. Zudem äußerte sie sich distanziert über das Kaffeehausmilieu: „[S]ie [hatten] sooo recht [...], als Sie damals vom Tisch des Herrenhofes sagten, dass jeder sich dort Versammelnder ein Bösewicht sei“ (an Arne Laurin, Wien, 10.2.1921, LA PNP, AL). Gleichzeitig stand E. von Allesch jedoch mit Musil in telefonischem Kontakt (sie verhandelten u. a. über eine illustratorische Mitarbeit Martha Musils an der künftigen Moderubrik der Prager Presse, vgl. E. von Allesch an A. Laurin, 1.3.1921; R. Musil an A. Laurin, Wien, 2.3.1921 - Robert Musil, Briefe 19011942, S. 217-218).

18. Wien, 2.3.1921 - Robert Musil, Briefe 1901-1942, S. 216. In ähnlicher Weise warb Musil auch um den Berliner Psychologen Johannes von Allesch (24.3.1921; ebd., S. 222-223; „ich habe das Wiener Kunst- und Theaterreferat für die Prager Presse übernommen“, 
versuchte er, Otto Soyka als Mitarbeiter zu gewinnen, und erstellte eine Liste von Büchern, die als Rezensionsexemplare an O. M. Fontana geschickt werden sollten ${ }^{19}$. Mitte April wies Musil Laurin jedoch auf den Widerspruch zwischen den proklamierten Idealen und der Praxis bzw. dem Ruf des Blattes hin:

Sie haben mir seinerzeit zwei Direktiven gegeben, von denen ich bisher bei der Anwerbung von Mitarbeitern Gebrauch machen konnte: Sie sagten, das Blatt sei Organ Masaryks; und die Orientierung sei überstaatlich.

Dem entgegen ist hier die allgemeine Überzeugung: die Prager Presse ist ein Organ des tschechischen Außenministeriums und die Orientierung sei derart, daß die Deutschen in ihrem Widerstand gegen den tschechoslowak. Staat geschwächt werden sollen und dem Ausland Sand in die Augen gestreut werden soll.

Dies - so Musil weiter - habe bereits einige potenzielle Mitarbeiter verschreckt, die beinahe zugesagt hätten. Musils geopolitische Vorstellung widersprach einem System „rivalisierender Bestialstaaten“ wie auch dem Nachkriegsrevanchismus gegenüber Österreich und Deutschland. Er hoffte, dass es möglich sei, die Prager Presse dieser Vorstellung zumindest anzunähern, obgleich er sich „lebhaft vorstellen“ könne, „Welchen Eiertanz“ Laurin angesichts der diplomatischen Orientierung des Blattes und dessen Nähe zum tschechoslowakischen Außenministerium vollführen müsse. Er bot seine Dienste zur Propagierung einer solchen „Versöhnungspolitik“ an (wie auch die Hilfe weiterer Freunde - „Vor allem wohl Robert Müller[s] ${ }^{20 ")}$.

Laurins Antwort ist offenbar nicht erhalten geblieben. Fakt ist, dass weder Musil noch Müller ihre Zusammenarbeit mit dem Blatt einstellten (siehe Appendix 2). Ebensowenig erlahmte allerdings Musils Vorsicht. Als er abermals Johannes von Allesch zur Zusammenarbeit mit der Redaktion der Prager Presse einlud, fügte er folgende warnende und beklommene Worte hinzu:

Ich fühle mich aber verpflichtet - im Gegensatz zur Amtspflicht - Dir zu sagen, daß das Blatt als tschechophiles Unternehmen stark angegriffen wurde. Ich bin mit der Angabe engagiert worden, daß die Tendenz des Blatts übernational

schrieb er ihm) sowie um den Dichter Max Mell (Mitte April 1921 - ebd., S. 225: „ich wollte Sie fragen, ob Sie für die Prager Presse / das neue, wie ich hoffe bloß verleumdete Masaryk Organ / schreiben möchten").

19. R. Musil an A. Laurin, Wien, 9.3., 10.3. und 12.3.1921 - ebd., S. 218, 219, 221.

20. R. Musil an A. Laurin, Wien, 23.4.1921 - ebd., S. 226-229. 
sei, was mir läge, man sagt aber, sie sei antinational so eine Art tschechisches Kriegspressequartierzeugnis und aus dem Blatt selbst ist nicht recht klug zu werden. Ich fühle mich sehr exponiert in meiner Position und würde sie sicher aufgeben, wenn ich nicht materiell dadurch wieder in eine unmögliche Situation geriete ${ }^{21}$.

Musil trat auch weiterhin als Botschafter der Prager Presse auf, so u. a. in einem an Arthur Schnitzler adressierten Schreiben vom September 1921. Er hob den „Literaturteil“ des Blattes hervor, von dessen freien Mitarbeitern er u. a. H. Bahr, H. von Hofmannsthal, R. Müller, F. Werfel und R. Coudenhove-Kalergi nannte, und lud Schnitzler - im Namen der Redaktion - zur Beteiligung ein, „entweder mit einer Dichtung oder um zu irgend welchen Fragen Stellung zu nehmen ${ }^{22 “}$. Mitte November führt er in einem Brief an F. Blei insbesondere seine Verpflichtungen gegenüber der Prager Tageszeitung als einen der Gründe an, warum ihm die Zeit für eine größere literarische Arbeit fehle: „Ich habe seit einiger Zeit so viel zu tun mit Prager Presse, Ministerium und allem, was dazu kommt, worunter sich der Roman nicht befindet ${ }^{23 \text { “. }}$

$\mathrm{Zu}$ Musils Freundes- und Bekanntenkreis gehörte (obschon auf ihre Weise) auch Ea von Allesch, und auch F. Blei ist ihm zuzurechnen wenngleich E. von Allesch, als sie Laurin Mitte April 1921 einen Text Brochs über F. Blei anbot (eine „philosophische Glosse“, die in österreichischen Blättern schwer unterzubringen sei), ähnlich wie später Gina Kaus $^{24}$, gerade Blei als eine zentrale Figur hervorhob: „Herr Dr. Broch, den Sie vom Blei-Kreis her gewiss in Erinnerung haben, obwohl er selten in Wien anwesend ist ${ }^{25 "}$. Ihren Kontakt zur Redaktion der Prager

21. 1.6.1921 - ebd., S. 232 (Als bestehende Wiener Mitarbeiter der Prager Presse nannte Musil hier R. Müller, „G[ra]f. Coudenhove-Kalergi“ und H. von Hofmannsthal). Zum wirtschaftlichen Hintergrund von Musils Engagement vgl.: „Für den Kauf einer Wohnung kam Musil zustatten, daß er von der Prager Presse, die damals ein sehr angesehenes Blatt voll kultureller Bedeutung war, als ihr Wiener Theaterkorrespondent engagiert worden war. Damit war ein sehr ansehnliches Fixum verbunden, dessen Geldwert sich für Musil durch den guten Valutastand der Tschechenkrone noch vergrößerte" (in Karl Corino (Hg.), Erinnerungen an Robert Musil, Wädenswil, Nimbus. Kunst und Bücher, 2010, S. 101).

22. 11.9.1921 - Robert Musil, Briefe 1901-1942, S. 238. Schnitzler nahm die Einladung nicht an.

23. 14.11.1921 - ebd., S. 245 - Eine Woche zuvor hatte er in einem anderen Brief an Blei erwähnt, dass seine Arbeit für die Prager Presse in Form pauschaler Vorschusszahlungen vergütet werde (ebd., S. 243).

24. In Karl Corino (Hg.), Erinnerungen an Robert Musil, S. 91.

25. Wien, 16.4.1921, LA PNP, AL. Vgl. Herm. Bloch, „Der Schriftsteller Franz Blei (Zum fünfzigsten Geburtstag)“, in Prager Presse 1, 1921, Nr. 23, 20. 4., S. 3-4, weiterhin siehe Helga Mitterbauer, „Hermann Broch und Franz Blei: Untergehende Kultur, zerfallende Werte“, 
Presse (bzw. namentlich zu Laurin) entwickelten E. von Allesch wie auch F. Blei allerdings in eigener Regie. Ein wertvolles Zeugnis darüber sind die ergiebigen, in Laurins Nachlass erhaltenen Briefkonvoluten, die in beiden Fällen die Jahre 1921-1936 abdecken. Die Vermittlungsinitiativen, mit denen beide (Blei aus dem fernen München) zum Aufbau des zwischen Wien und Prag gespannten Mitarbeiternetzes beitrugen, lassen sich nur begrenzt oder schätzungsweise rekonstruieren. Ein wichtiger Fluchtpunkt der redaktionellen Kontakte mit Wiener Literaten war von Anfang an die literarische bzw. kunstkritische Sonntagsbeilage. Die Hintergründe der meisten dieser (vereinzelten oder auch wiederholten) Auftritte (siehe Appendix 2) konnte ich jedoch nicht zufriedenstellend klären.

Hinsichtlich der Beteiligung Albert Ehrensteins (der 1921 zwischen Wien und Bayern pendelte) lassen sich zumindest ein paar Indizien zusammentragen. Bekannt ist, dass Ehrenstein mit Laurin und Pick schon vor dem Krieg in Kontakt stand ${ }^{26}$. Ähnlich wie bei anderen Mitarbeitern war wohl auch für ihn der ökonomische Aspekt ausschlaggebend - er zögerte jedenfalls nicht, die Honorarfrage in der Korrespondenz mit Otto Pick zu thematisieren ${ }^{27}$. Im September 1921 reagierte er entrüstet auf die Bedingungen, an die der Verwaltungsrat von Orbis seine Mitarbeit zu knüpfen gedachte, und forderte, dass ihm die bislang nicht verwendeten Texte umgehend zurückgesandt würden. „Ein Blatt, dem ich nicht einen Vorschuß von nebbich 1350 č[echischen]. K[ronen]. wert bin, muß auf meine Mitarbeit verzichten“, schrieb er. „Es gibt schließlich auch andere Prager Blätter ${ }^{28 “}$. Aufgrund des offenkundigen Bemühens der Redaktion, sich seine Gunst zu erhalten, wie auch „im Hinblick auf [seine] alte Freundschaft mit Herrn Otto Pick“ versuchte Ehrenstein diese Zwistigkeiten jedoch Ende Oktober 1921 beizulegen, und zwar mit einem ausführlichen Vorschlag für ein verstärktes Engagement:

Ich wäre nicht abgeneigt, der Prager Presse unter bestimmten Bedingungen das Recht der Veröffentlichung meiner sämtlichen bisher erschienenen, erscheinenden und künftigen Arbeiten [zu] geben, gleichgültig, ob sie schon gedruckt sind oder erst im Manuskript vorhanden sind. Darüber hinaus würde ich Ihrem Blatt nicht nur mit meinen epischen, lyrischen und essayistischen

in Endré Kiss, Paul Michael Lützleler, Gabriela Rácz (Hg.), Hermann Brochs literarische Freundschaften, Stauffenburg, Verlag Brigitte Narr, 2008, S. 37-50, dort S. 42, wie auch Sarah McGaughey, „Hermann Broch und Ea von Allesch: Möbel und Mode“, ebd., S. 50-63.

26. Siehe seine Briefe an A. Laurin, LA PNP, AL.

27. A. Ehrenstein an [Otto Pick], Wien, 8. und 21.8.1921, LA PNP, AL.

28. A. Ehrenstein an O. Pick, Wien, 9.9.1921, LA PNP, AL. 
Originalarbeiten und Übersetzungen zur Verfügung stehen, sondern ihm auch regelmäßig über alle literarischen und künstlerischen Ereignisse, die entweder die Prager Presse oder mich interessieren, berichten. Ich denke bei dieser Art Mitarbeit keineswegs lediglich an Feuilletons und Aufsätze, ich würde mich auch über politische Fragen äußern und darüber hinaus, wo immer ich lebe, meine zahlreichen Beziehungen im Interesse der versöhnlichen Kulturpolitik Ihres Blattes dazu benutzen, der Prager Presse Mitarbeiter von Rang und Wert $\mathrm{zu}$ sichern - literarische sowohl als auch politische.

Als Entlohnung für diese Tätigkeit schlug Ehrenstein ein regelmäßiges monatliches Honorar von „1000 č. K.“ vor. Den Brief schloss er mit einer Erwähnung seiner jüngst unternommenen Vortragstournee "durch Deutschland und Holland“, die sicherlich auch in der Prager Presse „gute Früchte tragen wird ${ }^{2 \text { “. }}$. Wie aus seinen (bereits ausdrücklich an Laurin adressierten) Briefen der nachfolgenden Monate hervorgeht, ließ man von der Zusammenarbeit nicht ab - sie basierte jedoch auch weiterhin auf Vorschusszahlungen, d. h. de facto auf Schulden, um deren Abarbeitung man Ehrenstein regelmäßig bat ${ }^{30}$.

3.

In der redaktionellen Berichterstattung zu Wiener und allgemeineren österreichischen Themen dominierte während des gesamten Jahres 1921 Langsteins Signum „ $\Delta$ “ (ein Teil der Artikel blieb unter der Chiffre „Ly/ly" unsigniert ${ }^{31}$ ). Eine Zusammenstellung dieser kurzen Berichte und ausführlicheren Kommentare ergäbe eine bemerkenswerte, bislang

29. Prag, 27.10.1921, LA PNP, F. A. Laurin (geschrieben auf Papier mit dem vorgedruckten Briefkopf „Die Gefährten, Herausgeber Albert Ehrenstein, Wien, VII., Seidengasse 5-11, Waldheim-Verlag, Leipzig)“.

30. Einer dieser Briefe illustriert gut die Notwendigkeit einer wirklich übernational und mehrsprachig angelegten Erforschung des mitteleuropäischen Netzes von Plattformen (die Tageszeitung Tribuna [Tribüne] war tschechischsprachig, Laurin war noch Ende des Jahres 1920 in ihrer Redaktion tätig): „Otto Pick schrieb mir einmal, mein Vorschuß betrage nur noch 1000 č. K. - was sehr leicht abzutragen wäre, wenn die Prager Presse bald meine Prosabeiträge ,Seminar', ,Hellas` und ,Hn` brächte. An Kodiček sandte ich von hier aus zwei Beiträge für das Feuilleton, die Tribüne ließ aber nichts von sich hören - vielleicht haben Sie die Liebeswürdigkeit, Kodicek oder Hlawatsch bald einmal anzurufen, denn K. č. sind hier, wo man von 1000 č. K. monatlich leben kann, sehr wichtig" (A. Ehrenstein an A. Laurin, Nordseebad Langeoog, 24.6.1922, LA PNP, AL).

31. Diese Chiffre erschien erstmals in der Morgenausgabe vom 4. April; weiterhin vgl. z. B. Ly. [Wien], „Bundeskanzler Schober. Das Programm der österreichischen Beamtenregierung“, in Prager Presse 1, 1921, Nr. 86, 23.6., S. 1; ders., „Das Programm Dr. Schobers, ebd., Nr. 92, 29.6., S. 1. 
unentdeckte Chronik der Wiener und österreichischen (außen-)politischen Ereignisse wie auch des sonstigen Geschehens jener Zeit ${ }^{32}$. Das Thema der zwischenstaatlichen Diplomatie wirkte sich (wie die oben erwähnten Einwände Musils zeigen) auf die Beziehungen zwischen der Redaktion der Prager Presse und deren österreichischen Mitarbeitern potenziell problematisch aus. Das in der Prager Presse entworfene Bild von den Nachkriegsverhandlungen, deren Ergebnisse auch Österreich als Nachfolgestaat der besiegten Monarchie betrafen, orientierte sich vor allem an den Haltungen und Äußerungen E. Benešs ${ }^{33}$. Die primäre Leistung des für eine deutschsprachige Leserschaft bestimmten Blattes bestand in der Vermittlung des tschechoslowakischen Regierungsund Verwaltungsdiskurses (so erläuterte hier z. B. der Minister Václav Schuster den Inhalt eines Handelsabkommens zwischen der Tschechoslowakei und Österreich ${ }^{34}$ ). Österreichische Ereignisse (einschließlich

32. Zur Illustration siehe z. B. einen Bericht über den Rechtsstreit zwischen Karl Kraus und Roman Horlicz, Herausgeber des Blattes Glos Wiedenski ( $\triangle$, Karl Kraus als Kläger, Nr. 24, 21.4., S. 5-6), weiterhin $\Delta$, „Die Wiener Krise“, ebd., Nr. 65, 2.6., S. 3, ders., „Internationaler Frauenkongreß. Die Erziehung der Jugend“, ebd., Nr. 105, 12.6., Abendausgabe, S. 2; „Die innere Krise Ungarns“, ebd., Nr. 110, 17.7., S. 7; „Friedrich gegen Horthy. Eine Wiener Darstellung“, ebd., S. 8; [Wien], „Die Uebernahme des Burgenlandes“, ebd., Nr. 120, 27.7., Abendausgabe, S. 1; [Wien], „Die Uebernahme Westungarns“, ebd., Nr. 126, 2. 8., S. 2 (dort auch ly (Wien), „Die streitenden Monarchisten“); [Wien], „Wiener Pressestimmen“, ebd., Nr. 133, 9.8., Abendausgabe, S. 1; „Stimmen der Wiener Presse“, ebd., Nr. 134, 10.8., Abendausgabe, S. 1 (mit Paraphrasen von Texten aus den Blättern Reichspost, Neue Freie Presse, Arbeiterzeitung, Deutsch-österreichische Tageszeitung und Wiener Morgenzeitung); [Wien], „Oesterreich und die Tschechoslowakei. Mitteilungen Dr. Schobers über die Hallstätter Verhandlungen. - Definitiver Abschluß in einer neuen Zusammenkunft Schober - Beneš", ebd., Nr. 138, 14.8., S. 2; „Oesterreichs Außenpolitik“, ebd.; [Wien], „Monarchistische Propaganda in Oesterreich“, ebd., Nr. 141, 18.8., S. 1; [Wien], „Die Vereinigung des Burgenlandes mit Oesterreich“, ebd., Nr. 151, 28.8., S. 3-4; „Die Ziele des magyarischen Putsches. Friedrichs Pläne: Rückberufung Karls, Umsturz in Ungarn und in Oesterreich, Revolutionierung der Slowakei“, ebd., Nr. 155, 1.9., S. 2; „Wien gegen Karl“, ebd., Nr. 174, 20.9., Abendausgabe, S. 1; „Schwere Plünderungsexzesse in Wien“, Nr. 247, 2.12., S. 3 (hier auch Ly (Wien), „Straßenpolitik und ihre Folgen, ebd., Nr. 247, 2. 12., S. 1-2); [Wien], „Die Tiroler Fronde. Christlichsozialer Sturm und Drang“', Nr. 254, 9.12., S. 1; „Oesterreich vor dem Wendepunkt“, Nr. 259, 14.12., S. 1-2; [Wien], „Die Lage Oesterreichs. Von Bundeskanzler Dr. Schober (Aus einem Gespräch)“, Nr. 270, 25. 12., S. 5 (siehe auch Ly (Wien), Oesterreich und Mitteleuropa, ebd., Nr. 269, 24.12., S. 1).

33. Vgl. z. B. „Dr. Beneš über die wirtschaftlichen Sanktionen. Erklärungen im Ausschusse für Aeußeres. - Deutsche Fürsprecher der Habsburger“, ebd., Nr. 18, 15.4., S. 1. Zwei weitere während des ersten Erscheinungsjahres publizierte Texte stammen von Jaromír Doležal, damals tschechoslowakischer Konsul in Wien (siehe Appendix 2).

34. Václav Schuster, „Der Vertrag mit Oesterreich“, ebd., Nr. 41, 8.5., S. 3. - Darüber hinaus informierte die Prager Presse auch über Reaktionen der Vertreter anderer Staaten sowie über weitere Meinungen (u. a. in den Rubriken Erwägungen und Pressestimmen, 
solcher, die von der akuten Labilität der österreichischen Staatsgrenzen und von der Unsicherheit der innenpolitischen Ordnung zeugten) wurden regelmäßig auch im Rahmen komplizierterer, vielschichtiger und breiter angelegter außenpolitischer Kommentare aus der Feder der Redakteure (insbesondere wohl Emil Oplatkas und Ernst/Arnošt Hromadas) wie auch in gelegentlichen Beiträgen ideell nahestehender österreichischer Kommentatoren besprochen.

In tschechophilem Duktus erinnerte Fritz Telmann in der zweiten Aprilhälfte an Beispiele deutsch-tschechischer Interaktion im Wien der Vorkriegszeit ${ }^{35}$. Im Laufe des Jahres veröffentlichte er in der Prager Presse noch einige weitere Texte. „Eines kann ich aber ruhig als geborener Wiener, der mit allen Schichten der Bevölkerung in Kontakt steht, sagen: $\mathrm{Da}$ in Wien derzeit keine vorherrschende Stimmung für den Anschluß besteht", skizzierte er die Disproportion der Meinungen im Lande, die Differenzen in der Interpretation von staatlicher und nationaler Identität. „Sicher ist, daß außer einigen Gesangs- und Turnvereinen keine merkbare Stimmung für den Anschluß sich in Wien geltend macht, siehe den schwachen Besuch der Anschlußkundgebungen und daß der Wiener kaum auf die Dauer von den Stammtischen in Graz und Innsbruck sich deren politische Weisheit diktieren lassen wird." Altdeutschem Sentiment setzte Telmann die Idee eines kulturell souveränen Österreichertums entgegen:

Wir Österreicher waren, sind und werden, wenn wir uns überhaupt erhalten, Kolonialvolk sein, womit natürlich nicht an gewaltsame Eroberungen, sondern an friedliche Durchdringung unserer östlichen Nachbarn mit den Erzeugnissen unserer Kultur (das Wort im weitesten Sinne genommen) gedacht sein soll ${ }^{36}$.

in denen einheimische wie ausländische Presseartikel paraphrasiert wurden - was österreichische Periodika betrifft, insbesondere aus der Neuen Freien Presse oder aus der Wochenzeitung Die Wage, dem Wirtschaftsblatt Der Österreichische Volkswirt, etc.). Ein spezielles Genre waren unsignierte Texte „österreichischer Politiker“ - vgl. z. B. die mahnend-analytische Betrachtung Tschechoslowakische Hilfe für Oesterreich (ebd., Nr. 50, 18.5., S. 1-2). Darüber hinaus wurden Interviews aus anderen Blättern paraphrasiert - so z. B. ein Interview des Wiener Korrespondenten der Gazette de Prague mit dem österreichischen Bundeskanzler Mayr („Bundeskanzler Dr. Mayr über Oesterreichs Wiederaufbau“, ebd., Nr. 71, 8.6., S. 1).

35. Fritz Telmann, „Das Deutsch-tschechische Komitee in Wien. Erinnerung und Ausblick“, ebd., Nr. 24, 21.4., S. 2. - Vgl. E. Offenthaler, „Fritz Telmann“, in ÖBL 1815-1950. Bd. 14 (Lfg. 65), 2014, S. 243.

36. Fritz Telmann, „Der Unfug der Anschlußbewegung“, in Prager Presse 1, 1921, Nr. 51, 19. 5., S. 1. Siehe auch: „Während sich die österreichische Provinz in unfruchtbaren und schädlichen Anschlußkundgebungen austobt[,] die Schützenvereinsbegeisterung von ,anno Tobak' ihre Orgien feiert, fortwährend ,Schwüre' geleistet werden, die Niemand 
Vor dem Hintergrund eines Treffens zwischen dem österreichischen und dem tschechoslowakischen Präsidenten konstatierte Telmann in Österreich einen Mangel an bürgerlicher, d. h. nicht-monarchistischer, nicht-proletarischer staatlicher Loyalität. Er hoffte, das Treffen Masaryks und Hainischs könne eine symbolische Bestärkung sein, und glaubte, dass „dieser Tag für unser Bürgertum auch der Tag werde, an dem es sich darauf besinnt, daß seine Söhne bestimmt sind, die Zügel dieses Staates zu führen und daß es keinen besseren Bundesgenossen auf seinem Wege finden kann, als das freiheitsliebende tschechische Volk ${ }^{37 \text { " }}$

Eine spezielle Facette der Wiener und österreichischen Topologie des Blattes stammt von dem Essayisten Rudolf Olden, der historischpolitologischen Weitblick mit der Kraft der Reportage und eines wendigen Journalismus verband ${ }^{38}$. Anfang Juni 1921 ließ er - bei Betrachtung einiger Fragmente aus einer Kampagne für den Anschluss eines Teils von Österreich an Deutschland - ironisch einige charakteristische (antiwienerische) Elemente und Motive dieser Kampagne anklingen:

Es ist ein sehr schönes, eindrucksvolles Plakat und symbolisiert offenbar den furor teutonicus und die übermenschliche Kraft, mit der die Salzburger gegen die Trennung vom Deutschen Reich anrennen. Ironie liegt dem Alpenländler fern, sie ist eine schlechte Eigenschaft der Wiener und anderer Ausländer. [...] Man will von Wien nichts wissen, ja man steht dem „roten“ oder dem ,jüdischen“

[sic] verlangt, auf dem Berg Isel (Begleitmusik: ,Zu Mantua in Bauden', gemischter Chor), auf dem Schloßberg zu Graz, auf dem Poestlingberg bei Linz und überhaupt auf jedem Berg, der zum ,Schwören' geeignet ist, während dieser ganze Faschingszug politischer Verblendung an uns vorbeizieht, bereitet sich in Wien, der Kapitale, die an dem ganzen Unfug so gut wie kein Teil hat, von klugen Männern fleißig vorbereitet ein Werk vor, das, vielleicht nicht mit Absicht der Veranstalter, aber darum nicht minder Wirksam [sic], dem pseudopolitischen Geschwafel die produktive Arbeit, der selbstmörderischen Phrase der Demagogen den Lebenswillen regsamer Bürger gegenüberstellt" (Fritz Telmann, „Die Wiener Messe. 11.-17. Sept. 1921“, ebd., Nr. 66, 3.6., S. 4-5).

37. Fritz Telmann, „Für die Republik (Zur Begegnung Masaryk - Hainisch)“, ebd., Nr. 131, 7.8., S. 1; das Ereignis wurde in der Prager Presse umfassend reflektiert, siehe auch die Fotografien in der Bilderbeilage vom 21.8.1921 (Nr. 22, S. 1).

38. Erstmals: R. O., „Oesterreich kaiserlich gesinnt? Von einem österreichischen Politiker“, ebd., Nr. 15, 12.4., S. 2. Systematischer mit Wien verbunden war die Laufbahn Oldens (geb. 1885 in Stettin) in den Jahren 1918-1924, er arbeitete mit Benno Karpeles, dem Redakteur der Blätter Der Friede und Der Neue Tag, zusammen (vgl. Charmian Brinson, Marian Malet, Einleitung, in dies. (Hg), Rudolf Olden, Peter Olden, Briefe aus den Jahren 1935-1936, Göttingen (= Europäische Ideen, Heft 64), Bernert GmbH, 1987, S. 1-15; Ruth Greuner, „Rudolf Olden. Aktiver Humanismus“, in dies., Gegenspieler. Profile linksbürgerlicher Publizisten aus Kaiserreich und Weimarer Republik, Berlin, Buchverlag Der Morgen, 1969, S. 249-278). 
Wien mit Abneigung gegenüber. [...] Die Wiener sollen schauen, wo sie bleiben, sie können sich auch an die Tschechen oder Ungarn anschließen, wenn man sie dort vielleicht lieber hat ${ }^{39}$.

Olden scheute sich nicht, die fragile Identität des neuen österreichischen Staats aufzuzeigen, die Spannung zwischen Zentrum und Grenzregionen, die Paradoxe und Widersprüche in den politischen Vereinbarungen und Ideen wie auch in der Praxis ihrer Umsetzung. „Übrigens, um meine bescheidene staatsrechtliche Meinung zu äußern, dieses Leithabanat war kein Witz, sondern völliger Ernst“, lautet eine seiner ungarischen Beobachtungen.

Die Regierung von Felsőőr hat nicht nur Marken ausgegeben (ungarische mit Überdruck, Achtung Philatelisten!), sondern auch die tatsächliche Gewalt in dem Westungarn ausgeübt, wie seine Grenzen im Trianoner Vertrag festgelegt sind. Ungarn hat das Gebiet übergeben, Österreich hat es nicht übernommen, die Generalskommission war machtlos ${ }^{40}$.

Anfang Dezember verfolgte Olden aus nächster Nähe die Wiener Straßenunruhen und deren Ergebnis und ironisiert daraufhin das revolutionäre Echo, das ihnen in der konservativen Presse zuteilwurde ${ }^{41}$. Kurz darauf rezensierte er in der Prager Presse Heinrich Kanners Buch Kaiserliche Katastrophenpolitik ${ }^{42}$. Den Autor stellt er als einstigen Chefredakteur der Wochenzeitung und späteren Tageszeitung Die Zeit und als Repräsentanten einer politischen Meinung vor, welche die (erhoffte) Nachkriegsordnung vorwegnahm: „Er kämpfte für eine gerechte Behandlung der Nationen im alten Österreich-Ungarn und kämpfte also gegen die kriegerische Lösung des Nationenproblems ${ }^{43 \text { “ }}$. Als es der Redaktion der Prager Presse kurz darauf gelang, Kanner als treuen Mitarbeiter des Blattes zu gewinnen ${ }^{44}$, war dies im Grunde eine wenig über-

39. Siehe auch Oskar Baum, „Neue Musik und Wien. Von Paul Stefan“, ebd., Nr. 114, 21.7., S. 6-7, einige Tage später rezensierte Baum Egon Wellesz Buch Arnold Schönberg („Eine Schönberg-Monographie“, ebd., Nr. 117, 24.7., S. 7).

40. Rudolf Olden, „Einzug in Westungarn“, ebd., Nr. 232, 17.11., S. 4.

41. Rudolf Olden, „Wien nach der Plünderung“, ebd., Nr. 251, 6.12., S. 3.

42. Bereits zuvor hatte die Redaktion der Prager Presse einen Auszug aus Kanners Buch veröffentlicht - Heinrich Kanner, „Das Schicksal eines Kriegsgegners“, ebd., Nr. 206, 22.10., S. 3-4, Nr. 207, 23.10., S. 2-3, Nr. 212, 28.10., S. 2-3, Nr. 217, 2. 11., S. 2-3.

43. Rudolf Olden, „Katastrophenpolitik“, ebd., Nr. 265, 20.12., S. 3-4.

44. Angefangen mit dem Text Schattenrepubliken (ebd., Nr. 270, 25.12., S. 3-4); im Nachlass Arne Laurins (LA PNP) befindet sich ein umfangreiches Konvolut mit Briefen Kanners wie auch eine Sammlung handschriftlicher Vorlagen zu den gedruckten Texten. 
raschende Konsequenz seiner langjährigen Kontakte zu ebenjenen Vertretern aus tschechischen politisch-kulturellen Kreisen, die im neuen Staat mächtige, administrativ exponierte Posten einnahmen ${ }^{45}$.

Über das Wiener Geschehen (bzw. verschiedene „Wiener Symptömchen") - sei es eine Fahrt mit der Trambahn oder die Wiener Telefondienste $^{46}$ - berichtete auch Hans Hansen ${ }^{47}$. Egon Dietrichstein schildert eine Auktion mit Teilen aus dem Kleßheimer Interieur Ludwig Viktor von Habsburg-Lothringens - Symbolen eines vergangenen Lebens ${ }^{48}$. Einer Ruine der alten, aristokratischen Welt gleicht das Wien, das Walther Rode durchstreift (sein Text ist hier als Appendix 1 beigefügt ${ }^{49}$ ). Parallel zu dem politisch-kulturellen Bild Wiens und Österreichs vermittelte die Prager Presse ihrer Leserschaft auch ein gewisses Bild von der dortigen aktuellen Kunstszene. - Zum einen direkt, mittels gelegentlicher Auszüge aus literarischen Texten (siehe Appendix 2; ein separates Kapitel waren hierbei „Evas“ fast wöchentlich erscheinende Mode-Feuilletons), zum anderen (expliziter) in Form kunstkritischer Reflexionen. Die wichtigste Rolle spielte hierbei zweifellos Robert Musil, der Wiener Theaterinszenierungen rezensierte. Erwähnenswert sind zudem auch die musikwissenschaftlichen Studien Paul Stefans ${ }^{50}$.

45. Vgl. Vratislav Doubek, „Die Politik und die Moderne“, in Lucie Kostrbová, Kurt Ifkovits, Vratislav Doubek (Hg.), Die Wiener Wochenschrift Die Zeit (1894-1904) als Mittler zwischen der tschechischen und Wiener Moderne, Praha-Wien, Masarykův ústav [Masaryk-Institut] und Archiv AV ČR [Archiv der Akademie der Wissenschaften der ČR]-Österreichisches Theatermuseum, 2011, S. 19-57.

46. Hans Hansen, „Wiener Symptömchen“, in Prager Presse 1, 1921, Nr. 143, 20.8., Abendausgabe, S. 3; Ders., „Kleine Wiener Symptome. ,Beamtenabbau““, ebd., Nr. 240, 25.11., S. 5-6.

47. Nicht mit Sicherheit, eher spekulativ, kann Hansen mit dem aus Bayern stammenden Journalisten Hans Bodenstedt identifiziert werden, der das Pseudonym „Hans Hansen“ verwendet haben soll (vgl. den Artikel „Hans Bodenstedt“, in Hans-Michael Körner, Bruno Jahn (Hg.), Große Bayerische Biographische Enzyklopädie. Bd. 1. A-G, München, K. G. Saur, 2005, S. 191).

48. Egon Dietrichstein, „Haus Habsburg unter dem Hammer. Eine Wiener Auktion“, in Prager Presse 1, 1921, Nr. 36, 3.5., S. 5. Siehe auch das posthum erschienene Porträt der Fürstin Pauline Metternich-Sándor, das eventuell Ernst Hromada zugeschrieben werden kann: „Heute ist das geistige und gesellschaftliche Wien bedeutend ärmer geworden. Die geistreiche, sicherlich interessanteste Wienerin ist heute gestorben", ist dort zu lesen. Der Autor betont zudem die innige Beziehung der Fürstin zur tschechischen Musik (H., „Die Metternich“, ebd., Nr. 184, 30.9., S. 4-5).

49. Walter Rode, „Wiens zweite Schönheit“, ebd., Nr. 245, 30.11., S. 6.

50. Siehe auch Oskar Baum, „Neue Musik und Wien. Von Paul Stefan“, ebd., Nr. 114, 21.7., S. 6-7, einige Tage später rezensierte Baum Egon Wellesz Buch Arnold Schönberg („Eine Schönberg-Monographie“, ebd., Nr. 117, 24.7., S. 7). 
Der nicht unbeträchtliche Anteil des Wiener literarischen und intellektuellen Schaffens an der Prager Presse stieß nicht überall auf Begeisterung. So bemerkt z. B. der Prager Übersetzer und Kritiker Paul Eisner in einem Brief an Rudolf Pannwitz:

Die Presse beginnt eine geistige Gefahr zu werden. Nicht etwa, dass sie sich im literarischen Teil und in der Sonntagsbeilage mit französischem und Budapester Kitsch begnügen würde, wie es die anderen Prager deutschen Blätter tun. Nein, sie hält etwas auf hohes literarisches und geistiges Niveau. Niveau heisst bei ihr die Prager, Wiener und Berliner Judenmache (die nicht immer von Juden stammen muss), das Nachlaufen hinter jedem Lausbuben drein, der einen „Erfolg“ hatte, jede Eintagsfliege, jeder entlaufene Ladenschwengel, der eine Schnauze und eine Schreibe hat, der ganze Veitstanz des literarischen Betriebs.

Als Umsetzer und Wahrer der unseligen Tendenz bezeichnet Eisner O. Pick. In Verbindung mit der Geschäftemacherei, die er in der Literaturpolitik der Prager Presse sah, erwähnt er F. Werfel ${ }^{51}$. Eisners Ansichten entfaltet bald darauf auch Pannwitz in seinem Briefwechsel mit Otokar Fischer. Im Gegensatz zu den konsolidierenden politischen Bemühungen Masaryks und Benešs charakterisiert er schroff den Zustand der tschechischen Kultur, wobei er ausdrücklich auf „[den],geist' des literarischen teils der Prager Presse“ verweist: „unter dem wahne auf die höhe der zeit zu kommen wird eine inflation von aller art zersetztem und unechtem literatentum mit den schlechtesten instinkten zugelassen und man vergiftet sich nun auch noch mit Wien und Berlin ${ }^{52 《}$.

Fischer lehnt in seiner Antwort die Vorstellung einer organischen Repräsentativität des literarischen Teils der Prager Presse für das tschechische "geistige [...] Leben [...]" und die „čechische [...] Dichtung“" ab, „sind es ja auch Deutsche, in erster Reihe jüdische Literaten Prags, die an der Redaktion der besagten Beilage teilnehmen - nicht aber Čechen ${ }^{53}$ !“ Daran anknüpfend bringt Pannwitz seine Verwunderung darüber zum Ausdruck, wie es möglich sei, dass ein deutschsprachiges Organ eines tschechischen Ministerpräsidenten (damals E. Beneš) „literarisch von schlechten kleinen jüdischen literaten bestimmt wird

51. Marie-Odile, Thirouin (Hg.), Briefwechsel. Rudolf Pannwitz / Otokar Fischer / Paul Eisner, Stuttgart, Cotta, 2002, S. 379, 380 (undatierter Brief).

52. Ebd., S. 113 (Dalmatien, Koločep kod Gruža, 2. 12. 1921; hier wie auch im Weiteren berücksichtige ich die Originalorthografie des zitierten Textes, die auch von der Herausgeberin des oben genannten Briefwechsels beibehalten wurde: Pannwitz' Verzicht auf die Großschreibung bei den meisten Substantiven und das Fehlen eines Großteils der Satzinterpunktion).

53. Ebd., S. 115 (Prag, 7. 12. 1921). 
die es bis zur pornographie treiben“. Anschließend bezeichnet er die Achse „Berlin Wien München“ als Symbol „[einer] Antikultur“ und das „feuilleton“ der Prager Presse als ,ein zu beachtendes symptom“ für deren unselige Wirkung. „[W]arum bestimmen Sie als Tschechen nicht auch im literarischen teile, was Sie haben wollen? Warum die unwürdige Sklaverei gegenüber Berlin und Wien?"', fragt $\mathrm{er}^{54}$. Dieser entrüstete interne Trialog hatte jedoch auf die weitere Form des Blattes keinen Einfluss. Pannwitz bot der Redaktion auch weiterhin seine Texte an, Eisner und nach kurzer Zeit auch Fischer waren im Laufe der folgenden Jahre Stamm-Mitarbeiter des Blattes mit einem ausgeprägten Wiener Touch.

Übersetzung aus dem Tschechischen: Ilka GIERTZ

54. Ebd., S. 118, 119 (Dalmatien, Koločep kod Gruža, 14. 12. 1921). 


\section{APPENDIX 1}

\section{Walther Rode: Wiens zweite Schönheit}

Wie Flechten auf Baumrinden sehen sich jene Verfallsblößen an, die der vom Mauerwerk herabfallende Verputz überall in der Stadt an Palästen, öffentlichen Gebäuden, ja an Denkmälern freigelegt hat. Leichte Sprünge im Firnis von Wien treten auf; es dunkelt allgemach. Dem Bruder Inn, der neben den übrigen großen Nebenflüssen der Donau als allegorische Figur seine Nische in der Albrechtsrampe trotzig ausfüllt, dem Elternpaar Danubius zur Seite, haben sie die biedere Tiroler Rechte abgehauen; Theiß und Drau, wie angefordert und rechtskräftig enthaftet, machen Anstalten, aus ihrem steinernen Gewölbe nach den Sukzessionsstaaten abzuwandern, den Verband der Donaumonarchie auch im Symbol zu sprengen.

Der Reichsverlust, der Aschermittwoch des Zusammenbruches, haben tiefe Spuren in das Antlitz von Wien eingegraben, Säulen sind geborsten, allenthalben sprießt Unkraut hervor. Was das Reich geschaffen und getragen hatte, ist mit dem Reich verschwunden. Die Haugwitz, Berchtold, Desfour, Palffy, Beaufort und wie sie alle hießen, sind nicht nur andeutungsweise weg und haben nur zurückgelassen, was sie nicht davontragen konnten. Die schönsten Kavallerieoffiziere der alten Armee haben die historischen Paläste ihrer feudalen Kameraden so lange an der Hand gehabt, bis sie sie bei Glückselig, Kola und Konsorten an den Mann gebracht haben. Aus den Tanz- und Empfangssälen der adeligen Herrschaftshäuser werden Bureaus, Deckengemälde werden parzelliert; der Lakai wird durch den Saldokontisten, der Nachfahre des Raubritters durch den Generaldirektor verdrängt. Im Palais Harrach auf der Freyung hausen kleine Bankiers neben Antiquitätenhändlern. Im Palais Pallavicini, der entgötterten Hofburg gegenüber, wird an Empiremöbeln und Gemälden feilgeboten, was der erbgesessene gegen den neuen Reichtum nicht zu behaupten vermochte. Stadtbild des franzisko-josephinischen Wien, des Wien aus reichsgewaltiger Zeit, du stehst im Begriffe, aus Wirklichkeit und Leben in die stündlich verblassende Erinnerung eines aussterbenden Geschlechts zu übersiedeln. Wir machen es mit, wie eine Kulturschicht sich über die andere legt, wie die ihre erste Bestimmung überdauernden Werke des Menschen, im Zweckwandel der Dinge, Schauplatz neuen Lebens werden. Städtische Burgen, Wahrzeichen von Macht und Reichtum, werden wieder 
Stätten des Warenumsatzes und Gewerbefleißes. Dies ist der Kreislauf der Geschichte in alten Städten.

Zeit wäre es, daß Wien aus Sack und Asche emportauche. Die Baufälligkeiten der Stadt sind nicht unaufhaltsam, sie hätten eine dringendere Sorge der Stadtverwaltung zu sein, als die Gehalts- und Teuerungsansprüche von Tausenden überflüssig Angestellten. Aber der letzte Zweck dieses Staates war und bleibt der Diurnist und seine Erhaltung, mag alles darüber zur Ruine werden. Dennoch bringt auch die Verwahrlosung, die Patina der Republik, ihre Schönheiten mit sich: Schärfer und düsterer blicken Karyatiden und Brunnenfiguren, wilder und tiefer grünen die Gärten der Stadt.

Verwahrlosung und Verlumpung müssen nicht sein, aber die Umwandlung des Palastes in das Geschäftshaus muß sein. Nur unbelehrbare Untertanenromantik wird dem im Betrieb befindlichen Palast, der Galvanisierung anachronistischen Prunkes, jenem seinen Stil jahrhundertealten, gehäuften Reichtums nachtrauern, den wir auf der vierten Galerie auskosten durften. Vorüber ist die Zeit der Grafenherrlichkeit, die letzten Reste der Feudalität verschwinden; der Graf ist weg, es fällt sein Haus in Trümmer.

Wenn die Großen eines Zeitalters ihre Privilegien und Positionen nicht mehr halten können, kommt die kribbelnde Masse der Ausgesperrten von überallher und richtet sich flugs auf dem bisher durch die Macht des öffentlichen oder privaten Rechtes gebannten Territorium ein. Die Stadt Spalato, eine ganze, große, schöne Stadt, ist im Palast des Kaisers Diokletian untergebracht. So groß war dieser Kaiser, daß eine ganze Stadt Platz hat, wo er und sein Troß einst hauste. So hat nach der Flucht des Hofes die Vorstadtbevölkerung von Wien den Lainzer Tiergarten, das Jagdterrain der Kaiser in Wien, XIII., in Besitz genommen, dessen viele Kilometer lange Umfriedungsmauer niedergelegt, hundertjährige Bäume gefällt, den Eber erlegt, die künstliche Wildnis des Waldes gerodet und hunderte von Schrebergärten angelegt auf einem Gebiet, das eine einzige Familie sich inmitten einer Großstadt als Wildpark angemaßt hatte. Politische Umwälzung ist Depossedierung der Namensträger der niedergerungenen Ordnung. Sie bringt außerdem hervor, nach dem Gesetz der Korrelation, den Massenkonkurs ganzer Gesellschaftsklassen. Der unablässig wirksame Prozeß des Abkrachens unhaltbar gewordener Einzelner, der Umwandlung von Palästen in Hotels oder Innungshäuser beschleunigt und überstürzt sich; unter unseren Augen treten untere Schichten der Gesellschaft die Erbschaft von höheren an. Die Palazzi bleiben, ihre Bewohner wechseln. Wo sind 
sie hin, die Colonna, Aldobrandini, die Strozzi, Sforza, Medici und Vendramin? Aber ihre Paläste erfreuen noch immer, obgleich die Windel herausflattert und der Trödler der Rechtsnachfolger des Fürsten geworden. Niemand weiß - für wen er baut. Der von seinen Hausgöttern verlassene Palast, in welchem bürgerliches Leben sprießt, hat den Reiz eines Wirtshauses in einer Burgruine; es ist ein Palast für jedermann. Das Palais Palffy wird ein Bankhaus, hört aber dennoch nicht auf, ein Palais zu sein. Es wird Bankhaus und Palais zugleich. Wer kann sagen, ob dieses zweite Leben, jenseits seines ersten Zweckes, nicht das höhere, das bewußtere Leben des Gebäudes ist?

Die kaiserlichen Schlösser, die Schlösser der Großen, ihre Gärten und Spielplätze hatten den Märchenglanz der Absperrung. Das Volk stand draußen, und drinnen, für Auserwählte, war alle Herrlichkeit und Pracht. Dieser Kinderzauber ist überwunden. Das Wohnungsamt, die politische Macht der Massen und die Kapitalskraft der Export- und Importgesellschaft haben die Schlösser aufgebrochen; Wien ist proletarisiert und kommerzialisiert worden. Aber ein neuer Zauber übergießt es. In das Grau des bürgerlichen Tagesdienstes sind die goldenen Fäden der Vergangenheit eingesponnen. Der Reichtum der Vergangenheit ist ein Element des bürgerlichen Lebens geworden. Die große Vergangenheit Wiens wurde dem Gebrauch des Publikums überantwortet. Im Kaisergarten darf jedermann sich ergehen, im Schloß Schönbrunn wohnen, wer sich dort eine Wohnung ergattert. Man kann sich im Palais Harrach 10 Deka Salami kaufen und das Defizit der Staatsoper ist die höchst persönliche Sorge der Herren Steuerzahler geworden.

Die zurückgedrängten Feudalen nennen Oesterreich und den Staat der Tschechoslowaken Diebsrepubliken. Sie sehen nur ihren Niedergang und die letzte Besitzergreifung des Volkes, aber sie haben vergessen, daß auch schon im 13. Jahrhundert die nachmaligen Gründe des Hofärars keineswegs herrenloses Gut gewesen sind und daß sich das Volk von Wien mit den Waffen in der Hand gegen die Etablierung der ersten Habsburger gewehrt hat. An der Spitze jeder Herrschaft steht die Gewalt. Die Freude über unser Erbe lassen wir uns nicht von überlebten Sterbensunwilligen verkümmern. Über Verfall mögen die abgesägten Nutznießer des alten Oesterreich klagen. Wir halten es mit jenem Revolutionsdichter, der da gesungen hat: Doch das Schönste an Ruinen ist, daß sie Ruinen sind. 


\section{APPENDIX 2}

\section{Ea von Allesch}

[Eva], „Was die neue Mode bringt“, Ostern. Beilage der „Prager Presse", S. 23

[Eva], „Die Mode und ihre Trägerin“, Nr. 7, 3.4., Sonntags-Beilage, S. 12

[Eva], „Mode-Woche“, Nr. 13, 10.4., Sonntags-Beilage, S. 13

[Eva], „Für sommerliche Gartenfeste“, Nr. 20, 17.4., Sonntags-Beilage, S. 11

[Eva], „Sommerkleider für junge Mädchen“, Nr. 27. 24.4., SonntagsBeilage, S. 14

[Eva], „Die Mode und der Sport“, Nr. 41. 8.5., Sonntags-Beilage, S. 13

[Eva], „Renntoiletten“, Nr. 48, 15.5., Pfingsten 1921, S. 24

[Eva], „Mode im Hochsommer“, Nr. 54, 22.5., Sonntags-Beilage, S. 14

[Eva], „Ueber das Badekostüm“, Nr. 61, 29.5., Sonntags-Beilage, S. 18

[Eva], „Flirt“, Nr. 82, 19.6., Sonntags-Beilage, S. 14

[Eva], „In den Bergen. Ein schlichter Modefilm mit für Touristik maßgebenden Kostümzeichnungen“, Nr. 89, 26.6., Sonntags-Beilage, S. 14

[Eva], „Akzessorien“, Nr. 96, 3.7., Sonntags-Beilage, S. 14

[Eva], „Kindermoden“, Nr. 103, 10.7., Sonntags-Beilage, S. 14

[Eva], „Lingerie“, Nr. 124, 31.7., Sonntags-Beilage, S. 14

[Eva], „Es handelt sich um den Kopf“, Nr. 131, 7.8., Sonntags-Beilage, S. 14

[Eva], „Modehundstag. Ein alltägliches Sonnenmärchen“, Nr. 138, 14.8., Sonntags-Beilage, S. 13-14

[Eva], „Geschichte des Reitkleids“, Nr. 144, 21.8., Sonntags-Beilage, S. 14

[Eva], „Trotteur“, Nr. 165, 11.9., Sonntags-Beilage, S. 14

[Eva], „Sentimentalitäten und Mode“, Nr. 179, 25.9., Sonntags-Beilage, S. 14

[Eva], „Das moderne Mantelkleid und die Pelzkrawatte“, Nr. 186, 2.10., Sonntags-Beilage, S. 14

[Eva], „Dramen im Hauskleid“, Nr. 228, 13.11., Sonntags-Beilage, S. 15

[Eva], „Alexander Dumas père und die Kochkunst“, Nr. 235, 20.11., Sonntags-Beilage, S. 14 
[Eva], „Was wird nun wirklich getragen?“, Nr. 240, 25.11., SonntagsBeilage, S. 13

[Eva], „Nikolos Gaben“, Nr. 256, 11.12., Sonntags-Beilage, S. 13

[Eva], „Illustrierte Naturgeschichte der Wolltiere (Für den Schulgebrauch)“, Nr. 263, 18.12., Sonntags-Beilage, S. 14

\section{Hermann Bahr}

„Goethebuch“, Nr. 68, 5.6., Sonntags-Beilage, S. 11-12

„Pfauenschrei“, Nr. 214, 30.10., S. 5-6

\section{Hugo Bettauer}

[Wien], „Die nicht sterben können“, Nr. 207, 23.10., S. 5-6

\section{Franz Blei}

[München], „Erzählung am Kamin“, Nr. 41. 8.5., Sonntags-Beilage, S. $11-12$

„Das Narrenseil. Zwei Novellen von Kaspar Ludwig Merkl“, Nr. 110, 17.7., Sonntags-Beilage, S. 13

„Hölderlin“, Nr. 111, 18.7., Abendausgabe, S. 4

"Geld in Kote“, Nr. 111, 18.7., Abendausgabe, S. 4

„Borchardt“, Nr. 124, 31. 7., Sonntags-Beilage, S. 12-13

„Fräulein Tsui“", Nr. 131, 7.8., S. 5-7

„Britische Autoren und ein deutscher Verleger“, Nr. 131, 7.8., Sonntags-Beilage, S. 13

„Ein chinesisches Kochbuch“, Nr. 136, 12.8., S. 4

„Das Licht der Lüge“, Nr. 153, 30.8., S. 4-5

„Sonate (,Residenztheater', München, 24. September)“, Nr. 183, 29.9., S. 6

„Oestliches“, Nr. 186, 2.10., Sonntags-Beilage, S. 13

„Esthers Wahl. Eine talmudische Geschichte“, Nr. 192, 8.10., S. 4-5

„Schonungslose Lebenschronik“, Nr. 200, 16.10., Sonntags-Beilage,

S. $13-14$

"Cäsars Stunde“, Nr. 218, 3.11., S. 6

„Wedekind“, Nr. 226, 11.11., S. 4-5

„Der Schwierige“, Nr. 228, 13.11., Sonntags-Beilage, S. 14

„Theater in München. Hofea“, Nr. 234, 19.11., S. 6-7

„Stendhals Lucian Leuwen“, Nr. 246, 1.12., S. 5-6 
„Das unbekannte Spanien“', Nr. 246, 1.12., Abendausgabe, S. 4

„Die geistlichen Uebungen“, Nr. 248, Abendausgabe, S. 4

„Die Reden Gotamo Buddhos“, Nr. 251, 6.12., Abendausgabe, S. 4

„Neue Gespräche Goethes mit Eckermann“, Nr. 261, 16.12., S. 5-7

„Anatole France“, Nr. 266, 21.12., Abendausgabe, S. 4

„Der Tisch mit Büchern“, Nr. 269, 24.12., S. 3

„Aus der Weisheit des Ninon“, Nr. 270, 25.12., Weihnachten 1921, S. 22

\section{Hermann Broch}

„Der Schriftsteller Franz Blei (Zum fünfzigsten Geburtstag)“, Nr. 23, 20.4., S. 3-4

„Heinz Thiess: ,Prometheus“', Nr. 207, 23.10., Sonntags-Beilage, S. 15

\section{Richard N. Coudenhove-Kalergi}

„Tschechen und Deutsche“, Nr. 179, 25.9., S. 2

„Hundemoral und Menschenmoral“, Nr. 193, 9.10., Sonntags-Beilage, S. 11

„Persönlichkeit“, Nr. 200, 16.10., Sonntags-Beilage, S. 13-14

${ }_{2}$ Hyperethische Güte und Bosheit", Nr. 214, 30.10., Sonntags-Beilage, S. 13

"Genealogie der Hyperethik“, Nr. 221, 6. 11., Sonntags-Beilage, S. $13-14$

„Sanktion der Hyperethik. Instinktivistische Sanktion der Hyperethik“, Nr. 270, 25.12., Weihnachten 1921, S. 21

\section{Egon Dietrichstein}

[Wien], „Haus Habsburg unter dem Hammer. Eine Wiener Auktion“, Nr. 36, 3.5., S. 5

\section{Jaromír Doležal}

[Wien], „Die Odyssee des Moskauer Künstlertheaters“, Nr. 30, 27.4., S. 5-6

[Wien], „Der Kuttenberger Prozeß im Lichte der österreichischen Regierungsberichte“, Nr. 214, 30.10., Sonntags-Beilage, S. 11-13 


\section{Albert Ehrenstein}

„Neue Gedichte“, Nr. 13, 10.4., Sonntags-Beilage, S. 11

„Zukunft“, Nr. 20, 17.4., Sonntags-Beilage, S. 11

„Lukian von Samosata“, Nr. 61, 29.5., Sonntags-Beilage, S. 13

„Die Reden Gotamo Buddhos. Zum erstenmale übertragen von Karl

Eugen Neumann“, Nr. 147, 24.8., S. 3

„Briefe an Gott“, Nr. 165, 11.9., Sonntags-Beilage, S. 11

„Der Weltordner“, Nr. 206, 22.10., S. 4

„Gebet“, Nr. 221, 6.11., Sonntags-Beilage, S. 14

„Die Filmlöwen sind los“, Nr. 245, 30.11., S. 4

„Literatur“, Nr. 252, 7.12., S. 3-5

„Der Verführer“, Nr. 263, 18.12., Sonntags-Beilage, S. 11

\section{Carl Ehrenstein}

„Aus Zumpels Kindheit“, Nr. 54, 22.5., Sonntags-Beilage, S. 9

„Vergänglichkeit“, Nr. 214, 30.10., Sonntags-Beilage, S. 12

\section{Oskar Maurus Fontana}

„Arakanga“, Nr. 16, 13.4., S. 4

„Lebensdokumente Paul Gauguins“, Nr. 71, 8.6., S. 4-5

„Kunstbücher“, Nr. 75, 12.6., Sonntags-Beilage, S. 13

„Die Mutter und die Wölke“, Nr. 82, 19.6., Sonntags-Beilage, S. 12

„Unbekanntes von Baudelaire“, Nr. 124, 31.7., Sonntags-Beilage, S. 12

„Flaubert in Aegypten“, Nr. 130, 6.8., S. 5

„Der Briefwechsel Nietzsches und Strindbergs“, Nr. 144, 21.8., Sonntags-Beilage, S. 13

„Abbé Prévost d'Exiles: ,Geschichte der Manon Lescaut“, Nr. 144, 21.8., Sonntags-Beilage, S. 13

„Charles-Louis Phillipe: „Bübü vom Montparnass. Ein Roman. Deutsch von Camill Hoffmann“, Nr. 149, 26.8., S. 4

„Beim Wasserturm“, Nr. 165, 11.9., Sonntags-Beilage, S. 12-13

„,Der Tierkreis. Eine Anthologie‘, eds. Karl Soffel und Klabund“, Nr. 166, 12.9., Abendausgabe, S. 4

„Apuleius von Madaura. ,Der goldene Esel““, Nr. 166, 12.9., Abendausgabe, S. 4 
„Gustav Landauers literarisches Nachlass“, Nr. 207, 23.10., SonntagsBeilage, S. 12-13

„Um und von Chodowiecki“, Nr. 224, 9.11., Abendausgabe, S. 3

\section{Egon Friedell}

„Drei Passanten und eine Gasröhre“, ebd., Nr. 190, 6.10., S. 4-5

\section{Otto Fröhlich}

[Wien], „Alfred Grünewald: ,Karfunkel““, Nr. 177, 23.9., Abendausgabe, S. 4

\section{Alfred Grünewald}

[Wien], „Lied der Mauern“, Nr. 82, 19.6., Sonntags-Beilage, S. 12

[Wien], „Empfang“, Nr. 103, 10.7., Sonntags-Beilage, s. 13

„Nachbar“, Nr. 124, 31.7., Sonntags-Beilage, S. 13

„Greller Tag“, Nr. 179, 25.9., Sonntags-Beilage, S. 11

„Rückkehr“, Nr. 200, 16.10., Sonntags-Beilage, S. 15

\section{Paris Gütersloh}

„Bei uns zu Hause“, Nr. 179, 25.9., Sonntags-Beilage, S. 12 „Die Legende vom menschlichen Leibe“, Nr. 185, 1.10, S. 4 „Exkurs über drei Erzählungen von Karl Sternheim“, Nr. 195, 11.10., S. 5-7 „Max Brods ,Erlöserin““, Nr. 259, 14.12, S. 4-5

\section{Willi Handl}

„Eduard Vojan“, ebd., Nr. 61, 29.5., S. 5-6

\section{Hans Hansen}

„Wiener Symptömchen“, Nr. 143, 20.8., Abendausgabe, S. 3

„Drei Völker und diese Zeit“, Nr. 193, 9.10., Sonntags-Beilage, S. 11-12 [Wien], Kleine Wiener Symptome. „Beamtenabbau“, Nr. 240, 25.11., S. 5-6 


\section{Paul Hatvani}

[Wien], „Bekenntnis zur Graphik“, Nr. 48, 15.5., Pfingsten 1921, S. 22 [Wien], „Notiz über Chesterton“, Nr. 51, 19.5., S. 4

[Wien], „Irrfahrt. Notizen zu einem Roman“, Nr. 96, 3.7., SonntagsBeilage, S. 11

[Wien], „Lunapark“, Nr. 110, 17.7., Sonntags-Beilage, S. 13

[Tirol], „Alpensymphonie (Quasi una fantasia)“, Nr. 37, 13.8., S. 4

[Wien], „Emil Lucka: ,Fredegund“', Nr. 138, 14.8., Sonntags-Beilage, S. 13

[Wien], „Ueber die deutsche Literatur in dieser Zeit (Einleitung zu einem Bericht)“, Nr. 144, 21.8., Sonntags-Beilage, S. 12-13

„Bekenntnisse“, Nr. 165, 11.9., S. 5

„Chaplin, oder ,Die Ueberwindung der Kausalität“", Nr. 177, 23.9., S. 2-3

„Abendmahl“, Nr. 179, 25.9., Sonntags-Beilage, S. 13

„Eine Geschichte vom Maler Klee“, Nr. 185, 1.10, S. 4, S. 4-5

"Carl Einstein: ,Negerplastik“', Nr. 185, 1.10., Abendausgabe, S. 4

„Desmoulins“, Nr. 193, 9.10., Sonntags-Beilage, S. 12-13

„Boccaceis: ,Das Leben Dantes“, Nr. 226, 11.11., S. 7

\section{Max Hayek}

[Safed, dem Weisen], „Die Parabel vom Mann, der Zeit über Zeit hatte", übers. von Max Hayek, Nr. 124, 31.7., Sonntags-Beilage, S. 12

[Safed, dem Weisen], „Die Parabel vom Genughaben“, übers. von Max Hayek, Nr. 130, 6.8., S. 6-7

[Safed, dem Weisen], „Die Parabel vom ,Weißen Elefanten“, übers. von Max Hayek, Nr. 149, 25.8., Abendausgabe, S. 4

[Safed, dem Weisen], „Die Parabel vom Gabelfrühstück im Aermelkanal“" übers. von Max Hayek, Nr. 158, 4.9., S. 6

[Safed, dem Weisen], „Wie ich zum Stein der Weisen kam“, übers. von Max Hayek, Nr. 186, 2. 10., Sonntags-Beilage, S. 12

[Safed, dem Weisen], „Die Parabel von den alten und modernen Dingen", übers. von Max Hayek, Nr. 221, 6.11., Sonntags-Beilage, S. 14

[Safed, dem Weisen], „Die Parabel von der Abhängigkeit“, übers. von Max Hayek, Nr. 256, 11.12., Sonntags-Beilage, S. 12

[Safed, dem Weisen], „Die Parabel vom goldenen Haar“, übers. von Max Hayek, ebd., Nr. 268, 23.12., S. 5-6

„Drei Gedichte von Walt Whitman“, übers. von Max Hayek, Nr. 270, 25. 12., Weihnachten 1921, S. 18 


\section{Eugen Hoeflich (M. j. ben Gawriel)}

„Bananen“, Nr. 114, 21.7., S. 6

„Der Oelbaum“, Nr. 114, 21.7., Abendausgabe, S. 3

„Die Flöte“, Nr. 121, 28.7., S. 6

„Haus des Lebens“, Nr. 143, 20.8., S. 3

„Der Meister“, Nr. 147, 24.8., Abendausgabe, S. 4

„Aus den palästinensischen Schwänken des Abu'l akl.“, Nr. 156,

2.9., S. 4-5

„Fluchtversuch“, Nr. 179, 25.9., Sonntags-Beilage, S. 12-13

„Tod eines Hundes“, Nr. 235, 20.11., Sonntags-Beilage, S. 11

„Jüdisches Theater“, Nr. 259, 14.12., S. 7

\section{Hugo von Hofmannsthal}

„Der Ersatz für die Träume. Eine kleine Betrachtung“, Nr. 1, 27.3., Ostern. Beilage der „Prager Presse“, S. 17-18

„Napoleon. Zum 5. Mai 1921“, Nr. 38, 5.5., S. 1-2

\section{Heinrich Kanner}

„Das Schicksal eines Kriegsgegners“, Nr. 206, 22.10., S. 3-4, Nr. 207, 23.10., S. 2-3, Nr. 212, 28.10., S. 2-3, Nr. 217, 2.11., S. 2-3

[Wien], „Schattenrepubliken“, Nr. 270, 25.12., S. 3-4

\section{Fritz Lampl}

„Das Lächeln der heiligen Tristitia“, Nr. 186, 2.10., Sonntags-Beilage,

S. 11-12

„An einen Schmetterling“, Nr. 200, 16.10., Sonntags-Beilage, S. 13

„Vita nuova. Das siebente Sonett aus Dantes Vita nuova“, übers. von

Fritz Lampl, Nr. 235, 20.11., Sonntags-Beilage, S. 13

„Heimgang“, Nr. 263, 18.12., Sonntags-Beilage, S. 11

\section{Robert Musil}

„Zusammenhänge?", Nr. 3, 30.3., S. 3-4

„Moskauer Künstlertheater“, Nr. 25, 22.4., S. 3-4

„Theaterabend“, Nr. 37, 4.5., S. 3-4

[Wien], „Stilgeneration oder Generationsstil“, Nr. 47, 14.5., S. 4 
„Die Schwärmer (Szene aus dem zweiten Akt)“, Nr. 48, 15.5., Pfingsten 1921, S. 17

[Wien], ,,Das Frühlingsfest in Florenz' von Forzano“, Nr. 56, 24.5., S. 6 „Ein Volkstück (Die Rax. Ein Wiener Schauspiel von Hans Stiftegger. Uraufführung am Deutschen Volkstheater in Wien)“, Nr. 72, 9.6., s. 5-6 „Das Drama eines deutschen Mannes. Hans Kohlhase“, Nr. 75, 12.6., S. 7-8

„Helden“, Nr. 78, 15.6., S. 5

„Moissi-Epilog“, Nr. 82, 19.6., S. 6

„Johann Strauß als Riese“, Nr. 99, 6.7., S. 6-7

„Wiener Saisonbeginn“, Nr. 160, 6.9., S. 5

„Wiener Theatermesse“, Nr. 163, 9.9., S. 3

„Wiener Theater. 'Der Meister' von Hermann Bahr“, Nr. 182, 28.9.,

S. 7-8

[Wien], „Moissi-Gastspiel“, Nr. 189, 5.10., S. 6-7

[Wien], „Der Dichter am Apparat", Nr. 198, 14.10, S. 4

„Wege zur Kunstbetrachtung“, Nr. 200, 16.10., Sonntags-Beilage,

S. $14-15$

„Wiener Nachträge“, Nr. 205, 21.10., S. 5-6

„Die Maus auf Fodara vedla“, Nr. 214, 30.10., Sonntags-Beilage, S. 12

"Valutaspekulation oder: Von Molière über Sternheim zu Kaiser",

Nr. 223, 8.11., S. 5

„Der Komiker", Nr. 230, 15.11., S. 5-6

„'Madame Legros'. Anläßlich der Aufführung in Wien“, Nr. 249, 4.12., S. 4

„Georg Kaiser-Matinee in Wien“, Nr. 268, 23.12., S. 6-7

„Begräbnis in A.“, Nr. 270, 25.12., Weihnachten 1921, S. 18

[Wien], „Jeßner und Brand“, Nr. 272, 28.12., S. 5-6.

\section{Robert Müller}

„Der Flieger“, Nr. 7, 3.4., Sonntags-Beilage, S. 3

„Kurfürstendamm“, Nr. 14, 11.4., Abendausgabe, S. 4

„Hans Flesch: Balthasar Tipho“, Nr. 94, 1.7., Abendausgabe, S. 4

„,Das Brandmal'. Roman von Emmy Hennings“, Nr. 96, 3.7., Sonntags-Beilage, S. 13

„„Der Mensch ohne Maske` von Vinicio da Veiga“, Nr. 96, 3.7., Sonntags-Beilage, S. 13-14 
„Kulturpolitik und Journalismus in Oesterreich“, Nr. 103, 10.7., Sonntags-Beilage, S. 12-13

„Vermännlichung der Frau“, Nr. 115, 22.7., S. 3

"Spengler und der historische Pessimismus", Nr. 121, 28.7., S. 5-6

„D'Annunzio“, Nr. 151, 28.8., Sonntags-Beilage, S. 18

„Der deutsche Jude“, Nr. 169, 15.9., S. 5

„Knut Hamsun“, Nr. 182, 28.9., S. 6

„Robert Musils, Schwärmer“", Nr. 191, 7.10., S. 7

„Max Picard: 'Der letzte Mensch'“, Nr. 193, 9.10., Sonntags-Beilage, S. 13

„Die Zukunft des Films“, Nr. 198, 14.10, S. 7

„Americano!“, Nr. 235, 20.11., Sonntags-Beilage, S. 11-13

„Hans Ferdinand Redlich: Gustav Mahler“, Nr. 235, 20.11., Sonntags-

Beilage, S. 15

„Der Todeskampf der weißen Rasse“, Nr. 246, 1.12., S. 6

„Bürger Meister Heinrich Mann (Zum Wiener Vortrag über ,Europä-

isches Denken')“, Nr. 252, 7.12., S. 5-6

„Die bronzene Rasse“, Nr. 270, 25.12., Weihnachten 1921, S. 21-23

\section{Rudolf Olden}

[R. O.], „Oesterreich kaiserlich gesinnt? Von einem österreichischen Politiker“, Nr. 15, 12.4., S. 2

„Wie man sich die Diplomatie vorstellt“, Nr. 17, 14.4., S. 1

[Wien], „Zivilmilitarismus“, Nr. 23, 20.4., S. 1

[Wien], „Was Europa geschah. Ein Amerikaner spricht über Europa“, Nr. 47, 14.5., S. 1-2

[Wien], Revolution und Justiz, Nr. 58, 26.5., S. 2

„Der Salzburger Abstimmungstag“, Nr. 65, 2.6., S. 3

„Davoser Geschichten“, Nr. 82, 19.6., S. 3-4

„Die verratene Revolution“, Nr. 88, 25.6., S. 4

„Restlose Erfassung“, Nr. 93, 30.6., S. 2

„Der klassenmäßige Zusammenschluß der geistigen Arbeiter“, ebd.,

Nr. 105, 12.7., S. 5-7

„Ein Tag aus dem Roman des Christoph Columbus, Nr. 124, 31.7., Sonntags-Beilage, S. 11-12

„Der Fall Wyneken“, Nr. 160, 6.9., S. 15-16

[Wien], „Duim, der Milliardendieb oder Wie wird man ,erste Hand““?, Nr. 191, 7.10., S. 4 
„Spekulation“, Nr. 203, 19.10., S. 5

„Die Vernichtung der Hohenzollern“, Nr. 216, 1.11., S. 3-4.

„Einzug in Westungarn“, Nr. 232, 17.11., S. 4

„Reigen-Epilog“, Nr. 235, 20.11., S. 5

[Wien], „Wien nach der Plünderung“, Nr. 251, 6.12., S. 3

[Wien], „Katastrophenpolitik“, Nr. 265, 20.12., S. 3-4

\section{Karl Renner}

„Vereinigte Staaten von Mitteleuropa“, Nr. 1, 27.3., S. 4

\section{Walther Rode}

[Wien], „Wiens zweite Schönheit“, Nr. 245, 30.11., S. 6

\section{Leo Slezak}

„Press Work“, Nr. 235, 20.11., S. 5-7

\section{Otto Soyka}

„Roman“, Nr. 61, 29.5., Sonntags-Beilage, S. 13-14

„Spiel“, Nr. 71, 8.6., S. 5-6

„Herman [sic] Koch“, Nr. 110, 17.7., S. 4

„Die Traumpeitsche“, Nr. 138, 14.8., Sonntags-Beilage, S. 13

\section{Paul Stefan}

[Wien], „Eine Jugendfreundin Gustav Mahlers“, Nr. 79, 16.6., S. 4 „Lucille Weingartner-Marcel“, Nr. 88, Abendausgabe, S. 2

„Anmerkungen zur Wiener Musik“, Nr. 202, 18.10., S. 7

„Musik in Wien“, Nr. 230, 15.11., S. 6

„Erinnerungen an die jüngste Wiener Musik“, Nr. 259, 14.12., S. 6-7 „In Holland“, Nr. 272, 28.12., S. 4-5

\section{Otto Stoessl}

„Die Schmiere“, Nr. 165, 11.9., S. 10 - Nr. 184, 30.9., S. 9.

„Das Gespräch“, Nr. 256, 11.12., Sonntags-Beilage, S. 12 


\section{Fritz Telmann}

[Wien], „Das Deutsch-tschechische Komitee in Wien. Erinnerung und Ausblick“, Nr. 24, 21.4., S. 2

[Wien], „Der Unfug der Anschlußbewegung“, Nr. 51, 19.5., S. 1

[Wien], „Die Wiener Messe. 11.-17. Sept. 1921“, Nr. 66, 3.6., S. 4-5

[Wien], „Für die Republik (Zur Begegnung Masaryk - Hainisch)“, Nr. 131, 7.8., S. 1

\section{Franz Werfel}

„Rede zu dem ,Vermächtnis eines Jünglings“", Nr. 75, 12.6., SonntagsBeilage, S. 11-12

„Zemlinsky“, Nr. 203, 19.10., S. 5-6

„Bocksgesang“, Nr. 214, 30.10., Sonntags-Beilage, S. 15, č. 216 Nr. 249, 4.12., S. 10.

„R. W. Raudnitz“, Nr. 239, 24.11., S. 5

„Spiegelmensch“, Nr. 249, 4.12., S. 4

„Lucie di Lammermoor. Aus dem Roman ,Die schwarze Messe“, Nr. 270, 25.12., Weihnachten 1921, S. 17

\section{Richard Wiener}

[Wien], „Ein neuer Minister“, Nr. 117, 24.7., Sonntags-Beilage, S. 12-13 [Wien], „Der Sanyassi und die Wahrheit“, Nr. 121, 28.7., S. 4-5

\section{Victor Wittner}

„Die Hornbrille“, Nr. 228, 13.11., Sonntags-Beilage, S. 12

„November“, Nr. 235, 20.11., Sonntags-Beilage, S. 11

„Der einsame Mensch“, Nr. 263, 18.12., Sonntags-Beilage, S. 12

\section{August B. Wolf}

„Leute im Theater", Nr. 121, 28.7., S. 4

„Von der Straße“, Nr. 131, 7.8., S. 6

„Filmen, nicht denken“, Nr. 138, 14.8., Sonntags-Beilage, S. 12

„Zu Dostojewskis ,Arme Leute“', Nr. 207, 23.10., Sonntags-Beilage, S. 15 „Abendlied“, Nr. 256, 11.12., Sonntags-Beilage, S. 12 


\section{Stefan Zweig}

„Die Tragik der Vergesslichkeit“, Nr. 1, 27.3., Ostern. Beilage der „Prager Presse“, S. 19-20

„Albert Ehrenstein“, Nr. 204, 20.10., S. 6

„Dostojewskij", Nr. 228, 13.11., Sonntags-Beilage, S. 11 